\title{
Long-term enrichment enhances the cognitive behavior of the aging neurogranin null mice without affecting their hippocampal LTP
}

\author{
Freesia L. Huang, ${ }^{1}$ Kuo-Ping Huang, ${ }^{1}$ and Catherine Boucheron \\ Developmental Neuroscience Program, National Institute of Child Health and Human Development, National Institutes of Health, \\ Bethesda, Maryland 20892-4510, USA
}

\begin{abstract}
Neurogranin $(\mathrm{Ng})$, a PKC substrate, is abundantly expressed in brain regions important for cognitive functions. Deletion of $\mathrm{Ng}$ caused severe deficits in spatial learning and LTP in the hippocampal CAl region of mice. These $\mathrm{Ng}-/$ - mice also exhibit deficits in the amplification of their hippocampal signaling pathways critical for learning and memory. A short-term exposure to an enriched environment failed to improve their behavioral performances. Here, we showed that a long-term enrichment protocol for the aging mice was beneficial to the $\mathrm{Ng}-\mathrm{I}-$ as well as $\mathrm{Ng}+/+$ and $\mathrm{Ng}+/-$ mice in preventing age-related cognitive decline. Enrichment also caused an increase in the hippocampal CREB level of all three genotypes and $\mathrm{Ng}$ level of $\mathrm{Ng}+/+$ and $\mathrm{Ng}+/-$ mice, but not that of $\alpha \mathrm{CaMKII}$ or ERK. Interestingly, hippocampal slices of these enriched aging $\mathrm{Ng}-/-$ mice, unlike those of $\mathrm{Ng}+/+$ and $\mathrm{Ng}+/-$ mice, did not show enhancement in the high frequency stimulation (HFS)-induced LTP in the CAl region. It appears that the learning and memory processes in these enriched aging $\mathrm{Ng}-/$ - mice do not correlate with the HFS-induced LTP, which is facilitated by $\mathrm{Ng}$. These results demonstrated that long-term enrichment for the aging $\mathrm{Ng}-/-\mathrm{mice}$ may improve their cognitive function through an $\mathrm{Ng}$-independent plasticity pathway.
\end{abstract}

Aging is known to be associated with a decline in cognitive function in laboratory animals as well as in human. In laboratory rodents, young adults perform better and learn faster than the aged animals. On the other hand, these old animals when placed under an enriched environment can improve their learning capacity and perform as well as the young ones. It seems that the aged brain still retain appreciable plasticity for cognitive improvement (Kobayashi et al. 2002). Short-term enrichment (daily or continuously for 3-4 wk), however, does not exert a beneficial effect (Bennett et al. 2006), whereas long-term exposure (>10 wk continuously) to an enriched environment that includes social interaction, physical activities, as well as intellectual functioning can reduce age-related spatial memory decline (Frick et al. 2003). Most notably, long-term environmental enrichment enhances hippocampal neurogenesis fivefold in old age (Kempermann et al. 2002), improves cognition in model aged Alzheimer's transgenic mice (Arendash et al. 2004), and reduces the incidence and severity of age-related neurodegenerative disorders (Mattson et al. 2001).

Previously, we showed that neurogranin $(\mathrm{Ng})$ knockout mice $(\mathrm{Ng}-/-)$ exhibited severe deficiency in high frequency stimulation (HFS)-induced long-term potentiation (LTP) in the hippocampal CA1 area, which may be due to their reduced $\mathrm{Ca}^{2+}$ transients (Huang et al. 2004). These $\mathrm{Ng}-/-$ mice also perform poorly in the hippocampus-dependent tasks (Pak et al. 2000; Miyakawa et al. 2001). Treatment of acute $\mathrm{Ng}-/$ - hippocampal slices with pharmacological agents that activate NMDA receptor, protein kinase $\mathrm{C}$ (PKC), or protein kinase A (PKA) showed greatly attenuated responses in autophosphorylation of $\mathrm{Ca}^{2+} /$ calmodulin (CaM)-dependent protein kinase II (CaMKII), and activation of other downstream targets including ERK and CREB (Wu et al. 2002, 2003). We surmised that the cognitive deficits of these $\mathrm{Ng}-/-$ mice were likely caused by their retarded $\mathrm{Ca}^{2+}$ - and

\footnotetext{
1'Corresponding authors.

E-mail fhuang@mail.nih.gov; fax (301) 480-8010.

E-mail huangk@mail.nih.gov; fax (301) 496-7434.

Article is online at http://www.learnmem.org/cgi/doi/10.1101/lm.636107.
}

$\mathrm{Ca}^{2+} / \mathrm{CaM}$-modulated signaling. Most interestingly, among heterozygous mice $(\mathrm{Ng}+/-)$, their performances in Morris water maze seemed to correlate positively to their individual hippocampal Ng content (Huang et al. 2004). Our studies thus far have led us to propose that $\mathrm{Ng}$, having no enzymatic activity, regulates the neuronal signaling by a "mass-action mechanism", in which the higher the Ng level the better the amplification of neuronal signaling reactions.

Most recently, in an effort to improve the cognitive function of these $\mathrm{Ng}-/$ - mice, we exposed young adult mice for a short duration to an enriched environment. While the experimental conditions benefited the $\mathrm{Ng}+/+$, as well as the $\mathrm{Ng}+/-$ mice, in LTP and behavioral testing, it failed to improve the $\mathrm{Ng}-/$ - mice in these aspects (Huang et al. 2006). In the present study we adopted a long-term enrichment protocol including mandatory physical activity for aged animals to determine if this experimental approach could slow down the decline in cognitive function associated with aging. Similar to the results previously obtained from the adult mice, enrichment caused an increase in hippocampal CREB level of all genotypes, and Ng level and HFSstimulated LTP in aged $\mathrm{Ng}+/+$ and $\mathrm{Ng}+/-$ mice, but not in aged $\mathrm{Ng}-/-$ mice. Most unexpectedly, enrichment also improved cognitive behavioral performances of these aged $\mathrm{Ng}-/-$ mice as well as aged $\mathrm{Ng}+/+$ and $\mathrm{Ng}+/-$ mice. It appears that, during the aging processes, these Ng-null mice have developed an Ngindependent plasticity mechanism in response to the environmental stimuli that contributed to their improved learning and memory.

\section{Results}

\section{Effect of enrichment on animal behaviors}

\section{Barnes maze}

Many studies have documented the age-related spatial memory decline. In laboratory, aged rodents do not perform as well as the young ones in Morris water maze. In the present study, a less stressful land-based spatial navigation task, Barnes maze, was 
used for testing the aged animals. During the acquisition phase of the maze training, these aged animals exhibited a very slow learning curve among all groups (Fig. 1A). Very little progress was made during the initial two days of training (up to the sixth block) and their learning seemed to level off after the 10th block of trial. Magnitudes of progress among the various groups of mice were best represented in Figure 1B, where the average latency of the first three blocks and the last three blocks of training, designated as starting and ending, respectively, were illustrated. Comparing the starting and the ending latencies, it was clear that all groups of mice made significant progress $(P<0.001)$ at the con-
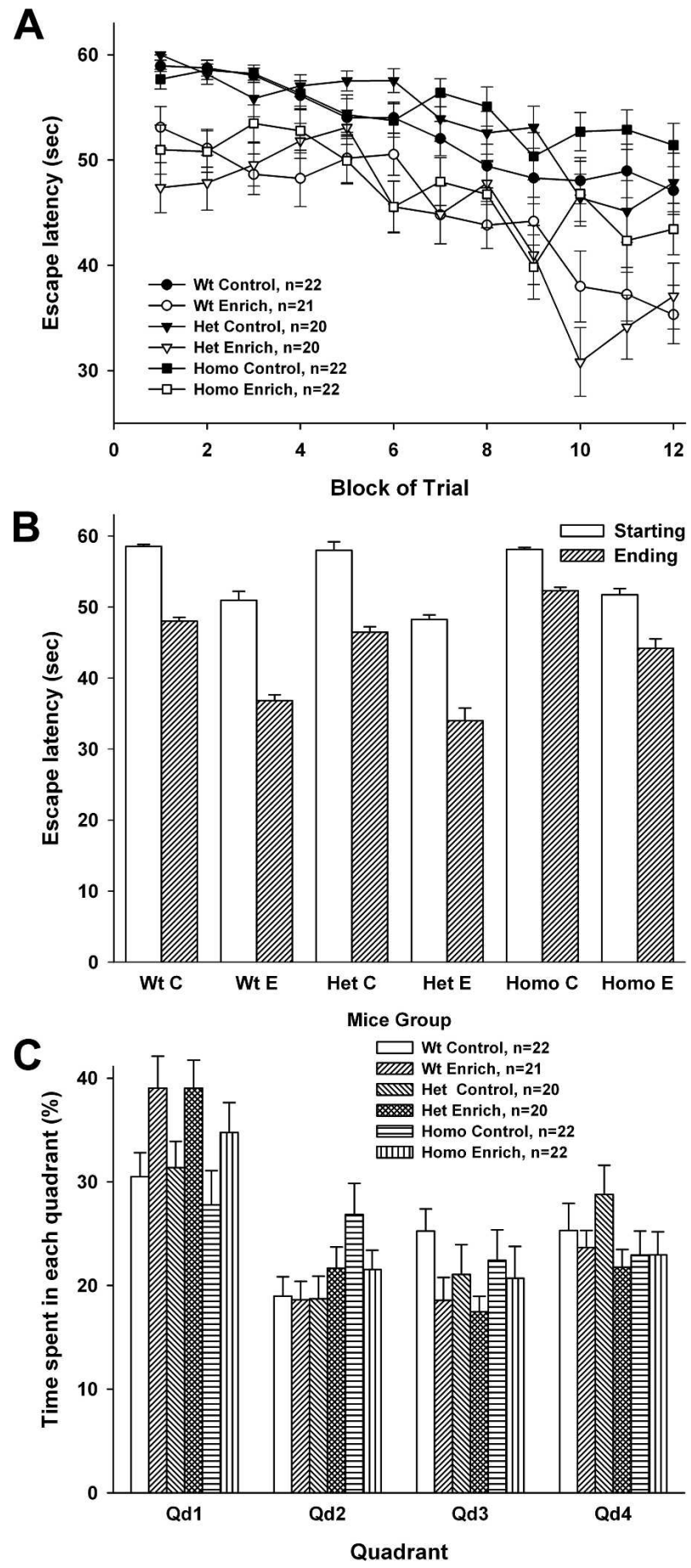

clusion of the training. It was also apparent that the enriched groups of $\mathrm{Ng}+/+$ and $\mathrm{Ng}+/$ - made significantly more progress than their respective controls and $\mathrm{Ng}-/-$ mice; but progress made by either control or enriched $\mathrm{Ng}+/+$ mice was not significantly different from that of $\mathrm{Ng}+/-$ mice, respectively. It was interesting to note that, while the control $\mathrm{Ng}+/+, \mathrm{Ng}+/-$, and $\mathrm{Ng}-/-$ had similar starting acquisition times $(58.6 \pm 0.3 \mathrm{sec}$, $n=22 ; 58.0 \pm 1.2 \mathrm{sec}, n=20 ; 58.1 \pm 0.3 \mathrm{sec}, n=22$, respectively), the enriched $\mathrm{Ng}+/+, \mathrm{Ng}+/-$, and $\mathrm{Ng}-/-$ mice also had similar starting latency times $(51.0 \pm 1.3 \mathrm{sec}, n=21 ; 48.3 \pm 0.7$, $n=20 ; 51.8 \pm 0.9 \mathrm{sec}, n=22$, respectively), which were much less than the starting latency times of the control groups. In fact, the enriched groups of all three genotypes showed reduced latency times comparing to their respective controls throughout the entire training period. These observations seem to suggest that the enrichment has enhanced their motivation to seek the escaping hole.

The mean acquisition times for the control mice in the last three blocks (10-12) of trial were: $\mathrm{Ng}+/+, 48.0 \pm 0.5 \mathrm{sec}$; $\mathrm{Ng}+/-$, $46.5 \pm 0.8 \mathrm{sec} ; \mathrm{Ng}-/-, 52.3 \pm 0.5 \mathrm{sec}$. While $\mathrm{Ng}+/+$ and $\mathrm{Ng}+/-$ were not significantly different from each other, both of them performed significantly better than $\mathrm{Ng}-/-$, with $P<0.005$ and $P<0.001$, respectively. The enriched $\mathrm{Ng}+/+(36.9 \pm 0.8 \mathrm{sec})$ and $\mathrm{Ng}+/-(34.0 \pm 1.8 \mathrm{sec})$ improved significantly over their corresponding controls, both with $P<0.001$. Most surprisingly, enriched $\mathrm{Ng}-/-(44.2 \pm 1.3 \mathrm{sec})$ also performed significantly better than their respective controls $(P<0.001)$. Thus, the present enrichment protocol had enhanced the motivation and performance of all three genotypes in the Barnes maze task. There was no significant difference in the average running speed among the groups (data not shown).

In the probe trial phase of Barnes maze the escape box was removed and the percentage of 1-min allowed time the mouse spent at the previous target hole and nearby area (quadrant 1)

Figure 1. Performances in Barnes maze as affected by environmental enrichment. $(A)$ The graph indicates the escape latency for finding the dark hiding hole for $\mathrm{Ng}+/+(\mathrm{Wt}), \mathrm{Ng}+/-$ (Het), and $\mathrm{Ng}-/-$ (Homo) mice over the successive blocks of trials. Mice received three blocks of trial per day and each block consisted of three trials with different starting locations. The average escape latencies for the last three blocks of trials among the various groups of mice were as follows (mean \pm SEM): $\mathrm{Wt}$ control, $48.0 \pm 0.5 \mathrm{sec}$; Wt enrich, $36.9 \pm 0.8 \mathrm{sec}$, Het control, $46.5 \pm 0.8 \mathrm{sec}$; Het enrich, $34.4 \pm 1.8 \mathrm{sec}$; Homo control, $52.3 \pm 0.5$ $\mathrm{sec}$; and Homo enrich, $44.2 \pm 1.3 \mathrm{sec}$. One-way ANOVA pairwise comparison by the Holm-Sidak method showed that both Wt and Het controls were significantly different from Homo control, with $P<0.05$ and 0.005 , respectively, but Wt control and Het control were not significantly different from each other. Enriched group of all three genotypes were also significantly different from their respective control groups all with $P<0.001$. (B) Average escaping time of the first three blocks and the last three blocks of trial. The differences between the starting and ending times represented the progress, and each group of mice made significant progress, all with $P<0.001$. For Wt and Het, both of their control and enriched groups made significantly more progress than the $\mathrm{Ng}-/-$ mice (all were $P<0.001$ ). The enriched groups of Wt and Het also made more progress than their respective controls, all with $P<0.001$. The progress made between Wt and Het; both their control and enriched groups, however, did not differ significantly. (C) During $1 \mathrm{~min}$ of the probe trial, the percentage time spent in quadrant $1(\mathrm{Qd} 1)$ where the escape box was located was as follows: Wt control, $30.5 \pm 2.3$; Wt enrich, $39.0 \pm 3.1$; Het control, $31.4 \pm 2.5$; Het enrich, $39.0 \pm 2.7$; Homo control, $27.8 \pm 3.3$; and Homo enrich, $34.8 \pm 2.9$. Their preference scores for the target quadrant over other quadrants for control/enriched mice were $1.4 \pm 0.1 / 2.3 \pm 0.4,1.5 \pm 0.2 / 2.1 \pm 0.3$, and $1.4 \pm 0.2 /$ $1.8 \pm 0.3$ for $\mathrm{Ng}+/+, \mathrm{Ng}+/-$, and $\mathrm{Ng}-/-$ mice, respectively (a value of 1 signified no preference). Enriched mice seemed to show more preference over their corresponding control mice; however, no significant difference was observed among various genotypes in control or enriched group by $t$-test comparison. 
was calculated as shown in Figure 1C. During the probe trial, the control $\mathrm{Ng}+/+, \mathrm{Ng}+/-$, and $\mathrm{Ng}-/-$ mice spent $30.5 \pm 2.3$, $31.4 \pm 2.5$, and $27.8 \pm 3.3$, respectively, percent of time in quadrant 1 ; and the enriched $\mathrm{Ng}+/+, \mathrm{Ng}+/-$, and $\mathrm{Ng}-/-$ mice spent $39.0 \pm 3.1,39.0 \pm 2.7$, and $34.8 \pm 2.9$, respectively, percent of time in quadrant 1 . Except the enriched $\mathrm{Ng}+/+$ mice that improved significantly $(P<0.05)$ over their control, all other pairwise comparisons were not significantly different. Comparison of the probe trial preference scores (time spent in quadrant 1 over averaged times spent in other quadrant) among control $\mathrm{Ng}+/+, \mathrm{Ng}+/-$, and $\mathrm{Ng}-/-$ mice showed that they displayed some preferences for quadrant 1 , with scores of $1.4 \pm 0.1$, $1.5 \pm 0.2$, and $1.4 \pm 0.2$, respectively. Enriched mice of all genotypes, though, showed increases in their preferences for quadrant 1 with scores of $2.3 \pm 0.4,2.1 \pm 0.3$, and $1.8 \pm 0.3$, respectively; they were not statistically different from their perspective controls.

\section{Step-down fear conditioning}

The step-down fear avoidance test is an emotional fear-motivated learning task. The animal associated the context of being on the platform inside the shock box (hippocampus-dependent spatial recognition) with the foot shock received when stepping down the platform (amygdala-dependent fear memory). During conditioning, we noticed that these aged animals behaved very cautiously to the novel environment comparing to their young adult counterparts in the previous study (Huang et al. 2006), especially the wild-type control, and they stayed at the platform for a much longer period of time (Fig. 2; $\mathrm{Ng}+/+, 142.6 \pm 37.3 \mathrm{sec} ; \mathrm{Ng}+/-$, $68.2 \pm 13.0 \mathrm{sec} ; \mathrm{Ng}-/-, 59.6 \pm 17.1 \mathrm{sec})$. Animals of enriched groups were even more cautious and lingering on the platform significantly longer than their respective control mice $(\mathrm{Ng}+/+$, $172.6 \pm 19.9 \mathrm{sec} ; \mathrm{Ng}+/-, 180.3 \pm 25.0 \mathrm{sec} ; \mathrm{Ng}-/-$, $147.2 \pm 20.1 \mathrm{sec})$. With the exception of $\mathrm{Ng}+/+$, enrichment significantly enhanced the cautious behavior of $\mathrm{Ng}+/-$ and $\mathrm{Ng}-/$ - mice over their respective controls to the novel environment $(P<0.001)$. Testing $24 \mathrm{~h}$ after foot shock revealed that all groups increased their latency times before stepping down the platform (control group: $\mathrm{Ng}+/+, 674.0 \pm 56.7 \mathrm{sec}$; $\mathrm{Ng}+/-$, $487.0 \pm 71.2 \mathrm{sec}$, and $\mathrm{Ng}-/-, 181.5 \pm 45.3 \mathrm{sec})$. Control Ng+/+ retained significantly longer than $\mathrm{Ng}+/-(P<0.05)$ and both $\mathrm{Ng}+/+$ and $\mathrm{Ng}+/$ - were also retained longer than $\mathrm{Ng}-/-$, with $P<0.001$. In the enriched groups, while $\mathrm{Ng}+/-(628.7 \pm 51.2$ sec) and $\mathrm{Ng}-/-(459.2 \pm 51.5 \mathrm{sec})$ significantly increased over their control $(P<0.05$ and $P<0.001$, respectively), enriched $\mathrm{Ng}+/+(693.0 \pm 52.8 \mathrm{sec})$ did not. Comparing the net increment in the latency time between enriched and control groups before and after training, it appeared that enrichment did not significantly improve the memory of either $\mathrm{Ng}+/+$ or $\mathrm{Ng}+/-$ mice. Surprisingly, only enriched $\mathrm{Ng}-/-$ mice showed a significant improvement in their performance in this task.

\section{Radial arm maze}

Learning in the eight-arm radial maze showed that the aged control mice of all three genotypes improved their performances during the course of training in all aspects, namely, time needed to retrieve all baits, and reference and working memory errors made (Fig. 3). It was apparent that these aged mice did not achieve as well comparing to the adult mice at the conclusion of the same training (Huang et al. 2006). The control mice of all three genotypes seemed to show similar learning curves with respect to time required to retrieve all four baits (Fig. 3A,a), which was $\sim 140 \mathrm{sec}$ at the end of the training. This level of performance was at least $20 \mathrm{sec}$ longer than the adult mice. During the early stage of trials, enrichment appeared to have little effect on their rates of learning; however, after extensive training (7-10 d,

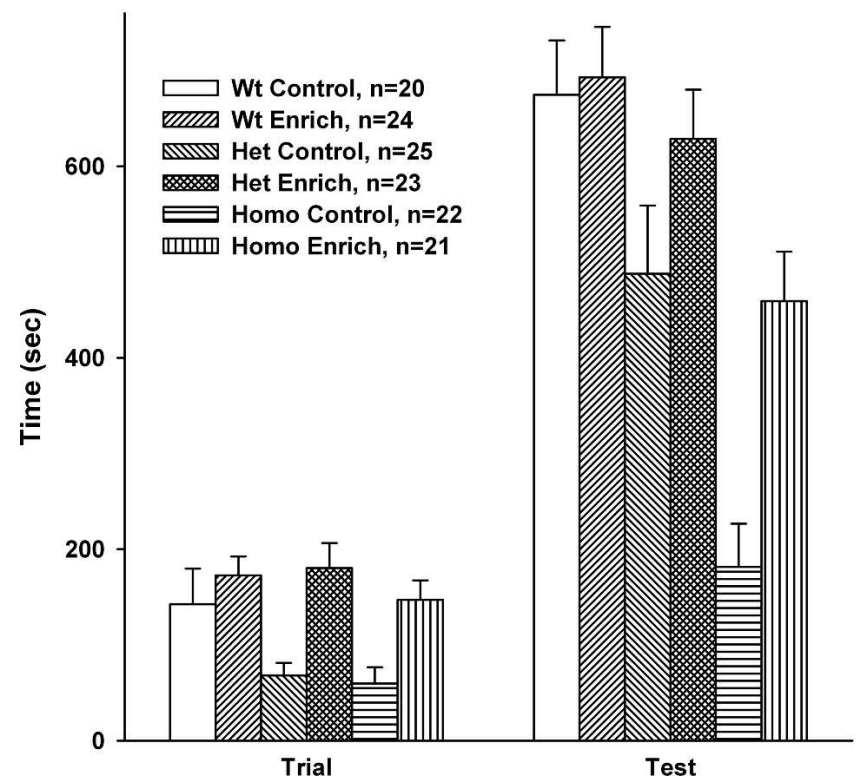

Figure 2. Effect of environmental enrichment on the step-down fear conditioning. During conditioning trial, these aged mice were very reluctant to step down and were allowed to remain on platform maximally for 15 min during testing $24 \mathrm{~h}$ later. Retention times for control/enrich during conditioning trials were 142.6 \pm 37.3/172.6 \pm 19.9, $68.2 \pm 13.0 / 180.3 \pm 26.0$, and $59.6 \pm 17.1 / 147.2 \pm 20.1$ for $\mathrm{Ng}+/+$ $\mathrm{Ng}+/-$, and $\mathrm{Ng}-/-$ mice, respectively; those during testing were, respectively, $674.8 \pm 56.7 / 693.0 \pm 52.8,487.8 \pm 71.2 / 628.7 \pm 51.2$, and $181.5 \pm 45.3 / 459.2 \pm 51.5$. All the retention times during testing were significantly different from those during conditioning. Retention times for enriched $\mathrm{Ng}+/-$ and $\mathrm{Ng}-/$ - were also significantly different from their control both during trial and testing. However, retention times for enriched $\mathrm{Ng}+/+$ mice were not different from control during either trial or testing, and that of enriched $\mathrm{Ng}+/$ - showed similar differences in retention time with control in both trial and testing. Thus, the enrichment protocol did not benefit $\mathrm{Ng}+/+$ mice, but exhibited a significant improvement for $\mathrm{Ng}-/$ - mice and a positive tendency for $\mathrm{Ng}+/-$ mice.

blocks 13-20) the enriched groups of all three genotypes exhibited significant improvement over their control cohorts (Fig. $3 \mathrm{~A}, \mathrm{~b}, \mathrm{c}, \mathrm{d})$.

For reference memory, all three groups exhibited clear learning curve; however, $\mathrm{Ng}-/$ - performed less well as compared to $\mathrm{Ng}+/+$ and $\mathrm{Ng}+/-$ mice. Both $\mathrm{Ng}+/+$ and $\mathrm{Ng}+/-$ mice reached the performance criteria ( $\sim 50 \%$ reference memory error) at the 13th trial while $\mathrm{Ng}-/$ - failed to do so even at the end of the 20 th trial (Fig. 3B,a). For comparison, adult $\mathrm{Ng}+/+$ mice reached performance criteria of $45 \%$ reference memory error at the 13 th trial (Huang et al. 2006). Enrichment apparently did not improve their reference memory in any of the genotypes (Fig. 3B,b,c,d); in fact, enriched $\mathrm{Ng}+/$ - mice were retarded somewhat in the acquisition of reference memory (Fig. 3B,c). For the working memory error, all control groups showed progress across the period of training (Fig. 3C,a). At the end of the trial, both $\mathrm{Ng}+/+$ and $\mathrm{Ng}+/-$ mice reached the criteria $(\sim 20 \%$ error), but $\mathrm{Ng}-/-$ did not. In comparison, adult $\mathrm{Ng}+/+$ made $15 \%$ working memory error (Huang et al. 2006). Enrichment exhibited no significant benefit for either $\mathrm{Ng}+/+$ or $\mathrm{Ng}+/-$, but it seemed to improve working memory of $\mathrm{Ng}-/-$ mice. Thus, at the conclusion of the training, $\mathrm{Ng}-/-$ seemed to perform as well as those $\mathrm{Ng}+/+$ and $\mathrm{Ng}+/-$ mice.

\section{Enrichment-mediated changes in hippocampal $\mathrm{Ng}$, $\alpha \mathrm{CaMKII}, \mathrm{CREB}$, and ERK expression}

Aging is known to cause loss of functional synapses and decrease the neurotransmitter-mediated responses. These changes are 

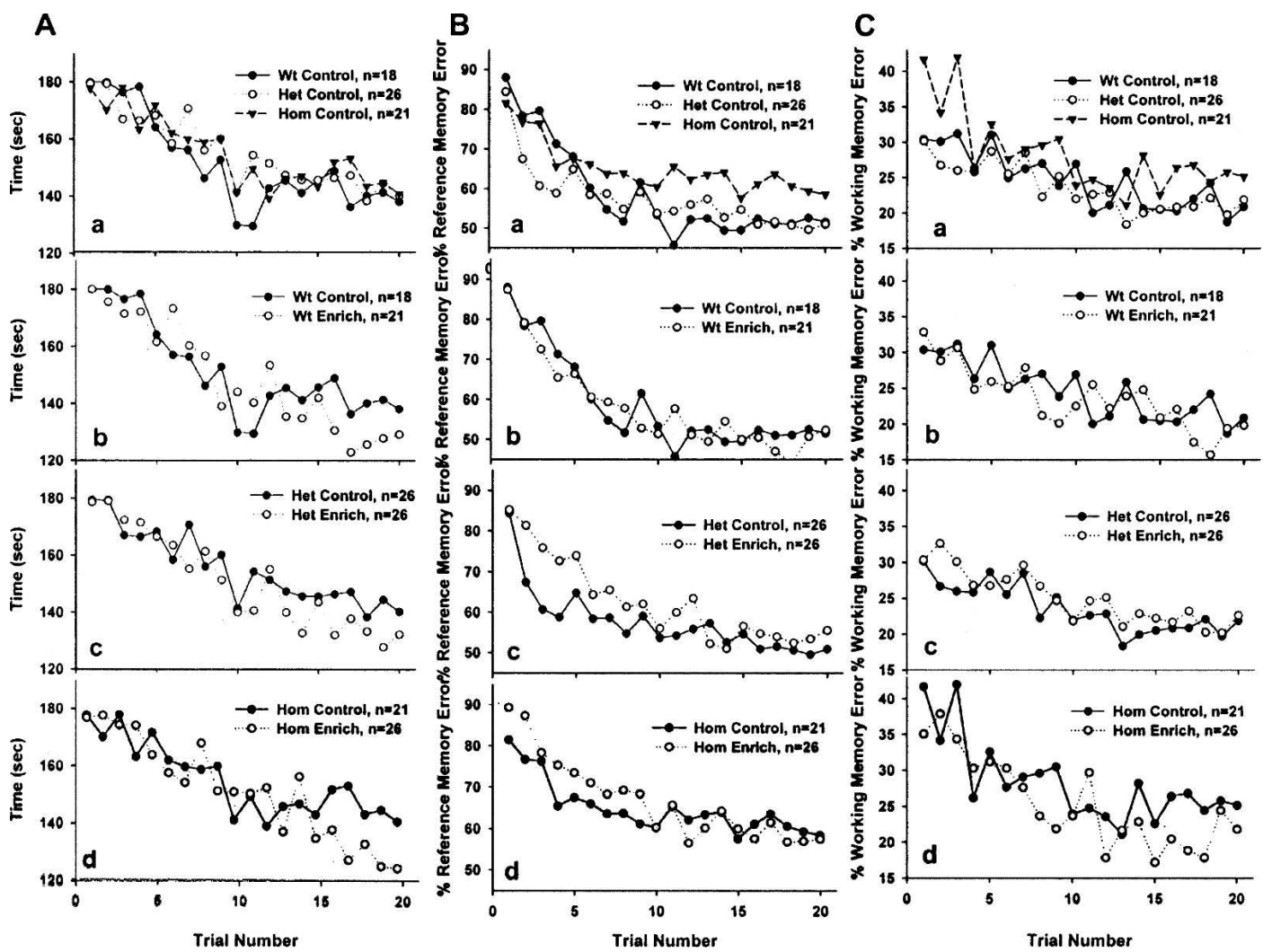

Figure 3. Performances in radial arm maze as affected by environmental enrichment. Mice were initially habituated in the maze with baits abounding and were trained with four baits constantly at arm number 1, 2, 4, and 7. There were two training trials per day for consecutive $10 \mathrm{~d}$. ( $A$ ) Progression of time required to retrieve all four baits or if $3 \mathrm{~min}$ had elapsed throughout 20 training trials. Averaged times for the last five trials among the various groups of mice were as follows: Wt control, $141.0 \pm 2.2 \mathrm{sec}$; and Wt enrich, $127.2 \pm 1.4 \mathrm{sec}(A b)$; Het control, $143.4 \pm 1.8 \mathrm{sec}$; and Het enrich, $132.7 \pm 1.6 \mathrm{sec}(A c)$; Homo control, $146.9 \pm 2.4 \mathrm{sec}$; and Homo enrich, $129.6 \pm 2.6 \mathrm{sec}(A d)$. Control mice of all three genotypes were similar in their performances $(A a)$. Enrichment group of each genotype improved their performances significantly over their respective controls with $P<0.001$ for all $(A b, c, d)$. (B) Percentage reference memory errors averaged from the last five trials were as follows: Wt control, $51.7 \pm 0.3 ;$ Wt enrich, $49.0 \pm 1.5 ;$ Het control, $50.8 \pm 0.3$; Het enrich, $54.1 \pm 0.5$; Homo control, $60.7 \pm 0.9$; and Homo enrich, $58.1 \pm 0.9$. Both Wt and Het control mice made significantly less error than that of Homo control with $P<0.001(B a)$. The enrichment protocol did not help these aged mice of any genotype in making less reference memory error $(B b, c, d)$. (C) Percentage working memory errors averaged from the last five trials were as following: Wt control, $21.3 \pm 0.9 ; \mathrm{Wt}$ enrich, $18.9 \pm 1.1$; Het control, $21.1 \pm 0.4$; Het enrich, $21.6 \pm 0.6$, Homo control, $25.7 \pm 0.4$; and Homo enrich, $20.7 \pm 1.2$. Homo control mice made significantly more errors than those of Wt and Het control with $P<0.001(\mathrm{Ca})$. After the enrichment, enriched Wt and Het mice did not improve any of their working memory $(C b, C c)$, whereas enriched $\mathrm{Ng}-/-$ mice made less error compared to their control $(P<0.001)$ and performed as well as $\mathrm{Ng}+/+$ and $\mathrm{Ng}+/-$ mice $(C d)$.

likely resulted from the reduction of certain essential signaling components. Figure $4 \mathrm{~A}, \mathrm{~B}$ shows representative immunoblot analyses of hippocampal Ng, $\alpha$ CaMKII, CREB, and p42 ERK expression from young adults and aged mice and the effects of enrichment on these proteins among the aged animals. Expressions of the housekeeping protein actin were also shown in the figure for the normalization purposes used in the bar-graphs (Fig. $4 \mathrm{C}, \mathrm{D})$. As shown in Figure $4 \mathrm{C}$, the aged $\mathrm{Ng}+/+$ mice exhibited a similar level of $\mathrm{Ng}(98.2 \pm 4.5 \%)$ and $\mathrm{Ng}+/-$ expressed only $47.8 \pm 2.4 \%$ that of adult $\mathrm{Ng}+/+$ mice $(P<0.001)$. Expressions of $\alpha$ CaMKII in $\mathrm{Ng}+/+, \mathrm{Ng}+/-$, and $\mathrm{Ng}-/-$ mice comparing to the adult were $84.9 \pm 6.4 \%, 90.3 \pm 5.6 \%$, and $95.0 \pm 7.1 \%$, respectively; and those of p42 ERK were $95.8 \pm 3.0 \%, 97.5 \pm 4.2 \%$, and $102.0 \pm 6.0 \%$, respectively. These expressions were not significantly different from those of adult or among different genotypes. Expressions of CREB among them $(80.2 \pm 2.3 \%$, $78.8 \pm 3.0 \%$, and $85.5 \pm 5.6 \%$, respectively), however, were significantly reduced from that of adult $\mathrm{Ng}+/+$ mice $(P<0.001$, $P<0.001$, and $P<0.005$, respectively).

Enrichment of the aged $\mathrm{Ng}+/+$ and $\mathrm{Ng}+/-$ (Fig. 4D) exhibited a significant increase in the $\mathrm{Ng}$ level $(121.6 \pm 3.4 \%$, $P<0.001$, and $116.9 \pm 4.1 \%, P<0.005$, respectively) over their controls. A significant increase of CREB was also observed for the enriched animals of all three genotypes $(\mathrm{Ng}+/+, 125.3 \pm 5.2 \%$; $\mathrm{Ng}+/-, 156.1 \pm 7.5 \%$; and $\mathrm{Ng}-/-, 156.8 \pm 5.2 \%)$, all with $P<0.001$. As the aged control mice of all three genotypes showed $20 \%$ reduction in CREB expression comparing to that of the adult $\mathrm{Ng}+/+$ mice (Fig. 4C), the enrichment had improved its expression in the aged mice to levels greater than that in the adult. Expressions of p42 ERK in enriched $\mathrm{Ng}+/+, \mathrm{Ng}+/-$, and $\mathrm{Ng}-/-$ mice $(102.4 \pm 3.1 \%, 107.8 \pm 5.4 \%$, and $104.1 \pm 3.10 \%$, respectively, over their controls) and expressions of $\alpha$ CaMKII $(106.3 \pm 29 \%, 105.5 \pm 4.3 \%$, and $107.3 \pm 4.6 \%)$ in the enriched mice were, however, not significantly different from their controls.

Effect of enrichment on LTP at hippocampal CAl area Previously, exposure of 3- to 5-mo-old young adult mice to an enriched environment for merely three weeks was enough to enhance LTP elicited by a single 1 -sec burst of $100 \mathrm{~Hz}$ stimulation for the $\mathrm{Ng}+/+$ and $\mathrm{Ng}+/$ - mice. Under the present electrophysiological recording conditions, such 1 -sec $100 \mathrm{~Hz}$ stimulation produced a potentiation in adult $\mathrm{Ng}+/+$ mice $(143.4 \pm 1.3 \% ; n=11 /$ 

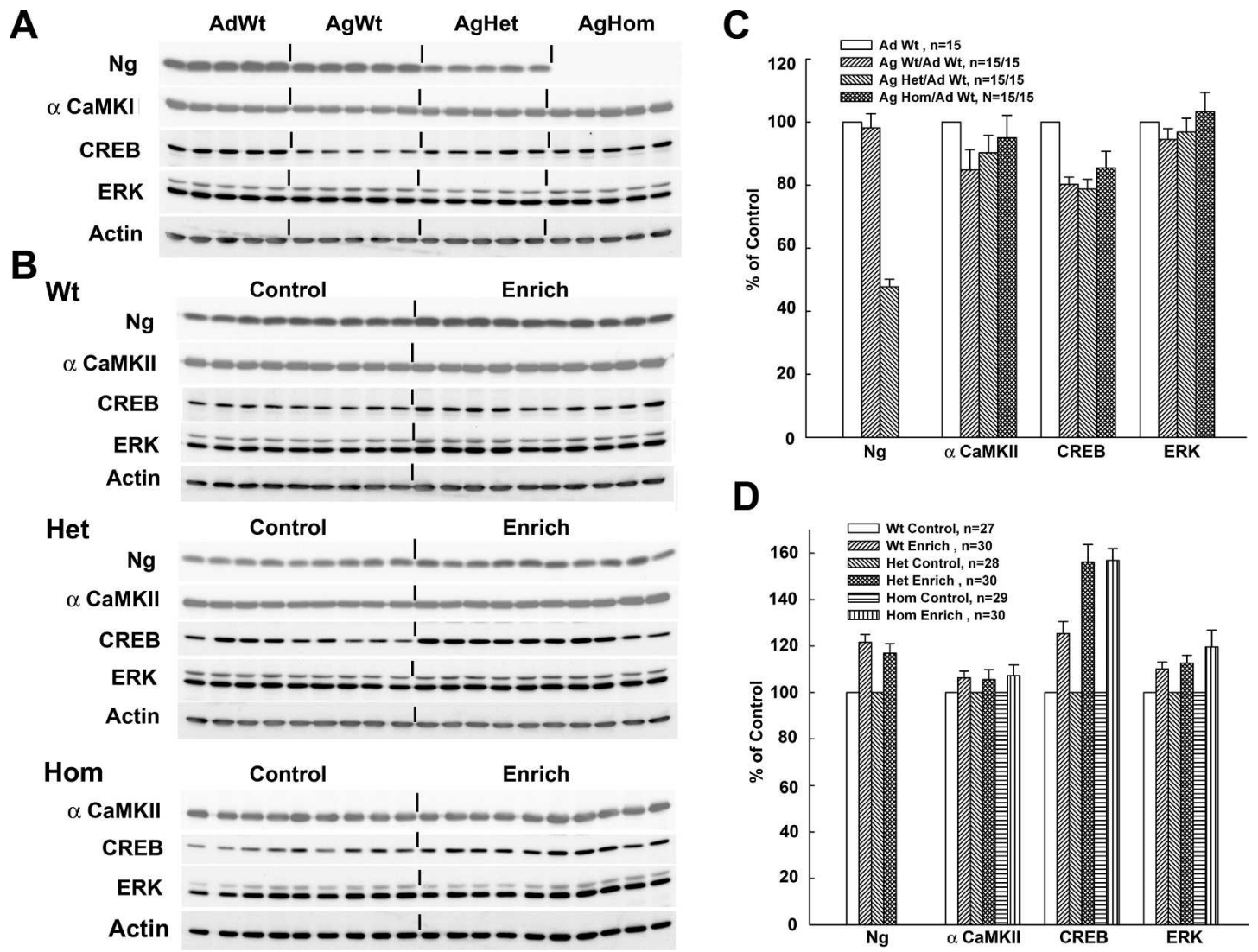

Figure 4. Immunoblot analyses for the hippocampal levels of $\mathrm{Ng}, \alpha \mathrm{CaMKII}, \mathrm{CREB}$, and ERK in the control and enriched mice. The lower portion of nitrocellulose membrane with transferred proteins was analyzed for $\mathrm{Ng}$, and the top portion was analyzed for $\alpha$ CaMKII, CREB, ERK, and actin consecutively after each stripping. (A) Representative immunoblots (one of three) comparing the levels of protein expression in adult Wt mice to those in aged mice of various genotypes. (B) Each set represented one of three immunoblots comparing the levels of protein expression in control and enriched aging $\mathrm{Wt}$, Het, and Hom mice. (C) Bar representations showing relative level of expression in the aging mice after normalizing with actin expression in comparing against adult Wt control. Aging $+/-$ mice expressed only $47.8 \pm 2.4 \%$ and aging Wt expressed comparable level of $\mathrm{Ng}$ comparing to adult Wt. Expressions of $\alpha$ CaMKII and p42 ERK in the aging mice of all genotypes were not significantly different from that of the adult. However, CREB expressions in the aging mice, $80.2 \pm 2.3 \%, 78.8 \pm 3.1 \%$, and $85.5 \pm 5.6 \%$, respectively, for $+/+,+/-$, and $-/-$ mice were significantly reduced from that of the adult mice. $(D)$ Bar representations comparing protein expression in enriched mice to those of their respective control mice after normalizing with actin expression. Both enriched $+/+$ and $+/-$ mice expressed significantly more $\mathrm{Ng}$ than their controls. Significant increases in CREB $(P<0.001)$ were also observed for all enriched mice compared to their controls. However, expressions of $\alpha$ CaMKII and p42 ERK in the enriched mice were not significantly different from their controls.

4), which was significantly greater than the aged control animals of the three genotypes: $\mathrm{Ng}+/+, 132.0 \pm 0.6, n=20 / 9 ; \mathrm{Ng}+/-$, $118.9 \pm 1.1 \%, n=18 / 8 ; \mathrm{Ng}-/-, 102.1 \pm 1.2 \%, n=17 / 8$. By one-way ANOVA with Dunn's method or $t$-test, all pairwise comparisons showed significant differences among all control groups of the aged animals, and comparing to adult $\mathrm{Ng}+/+$ mice, all with $P<0.001$ (Fig. 5). Enrichment has enhanced significantly the LTP in both $\mathrm{Ng}+/+(140.0 \pm 1.4 \%, n=19 / 10, P<0.005)$ and $\mathrm{Ng}+/-$ $(128.6 \pm 0.6 \%, n=22 / 10, P<0.001)$, whereas enriched $\mathrm{Ng}-/-$ (105.6 $\pm 0.9 \%, n=21 / 10, P=0.078)$ was not significantly improved over its control. It seemed that the aged animal did show age-related decline in LTP; however, they still have appreciable plasticity to be benefited from enrichment. Like adult $\mathrm{Ng}-/-$, aged $\mathrm{Ng}-/$ - did not show LTP and exhibited little plastic change by the enrichment process.

\section{Discussion}

The current study confirmed our previous results using adult $\mathrm{Ng}-/$ - mice that the aged $\mathrm{Ng}-/$ - mice also lacked enrichment-related enhancement of LTP in hippocampal CA1 region. Surprisingly, enriched environment did benefit certain aspects of the cognitive behaviors of these aged $\mathrm{Ng}-/-$ animals. $\mathrm{Ng}$ has been shown experimentally (Huang et al. 2004) and demonstrated by theoretical modeling (Zhabotinsky et al. 2006) to play a pivotal role in the enhancement of hippocampal synaptic plasticity. Environmental enrichment, which is known to increase neurogenesis in the rodents, enhances LTP and benefits the cognitive performances of mice, in part, by increasing the hippocampal level of $\mathrm{Ng}$ (Huang et al. 2006). However, without Ng, environmental stimuli fail to improve the cognitive function of young $\mathrm{Ng}-/$ - adult mice and their expression of LTP. It seemed the present enrichment procedure could improve some behavioral performances of these aged $\mathrm{Ng}-/-$ mice without improving their hippocampal LTP. In particular, the step-down fear avoidance test provided the most distinctive improvement for $\mathrm{Ng}-/-$ mice (Fig. 2). In contrast, enrichment did not produce a similar benefit for the aged $\mathrm{Ng}+/+$ or $\mathrm{Ng}+/$ - mice in this test, though they did improve in other tests. These findings suggest that the aging process may have altered the signaling mechanisms and that aged $\mathrm{Ng}-/-$ mice have well adopted the pathways less dependent on $\mathrm{Ng}$ in responding to environmental enrichment. It has been proposed that aging causes a shift in the synaptic plasticity mechanism (Lee et al. 2005; Huang and Kandel 2006), perhaps as a result of $\mathrm{Ca}^{2+}$ dysregulation (Rosenzweig 


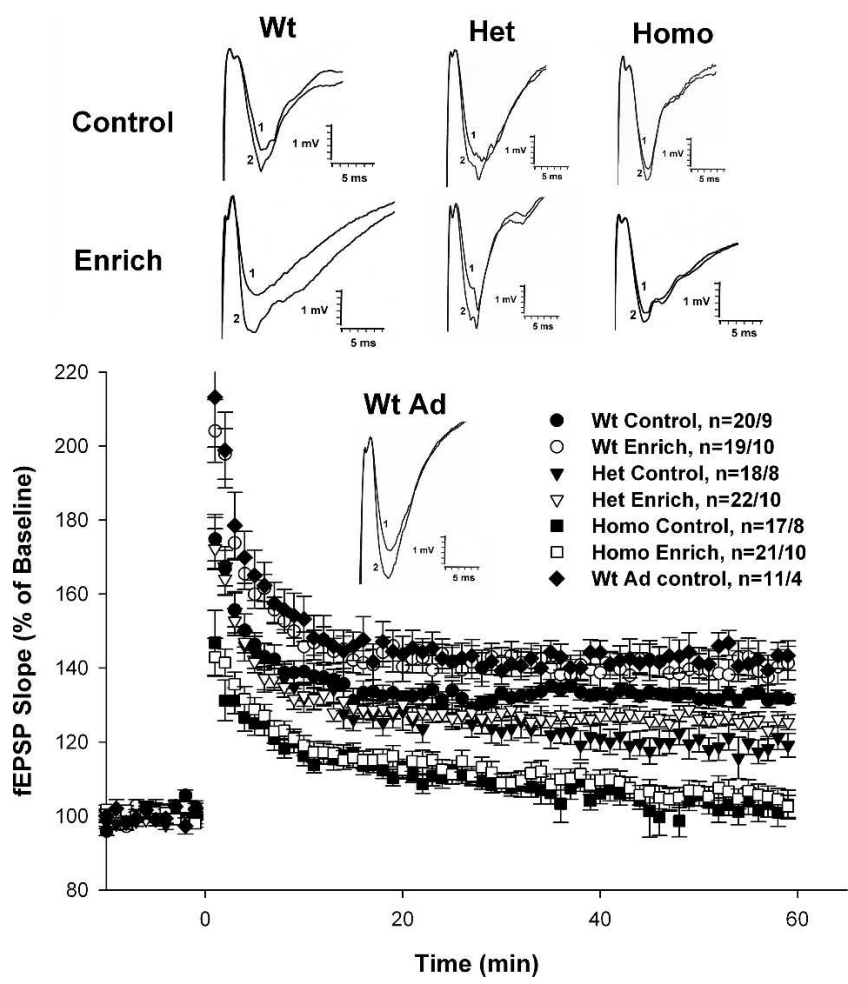

Figure 5. Effect of environmental enrichment on LTP in the hippocampal CA1 region. LTP was induced by HFS $(100 \mathrm{~Hz}$ for $1 \mathrm{sec})$, and the fEPSP at the CA1 region was recorded for $60 \mathrm{~min}$. The slope of the fEPSP was determined and the steady-state levels of responses among aged $\mathrm{Ng}+/+$ (Wt), $\mathrm{Ng}+/-(\mathrm{Het})$, and $\mathrm{Ng}-/$ - (Homo) as well as adult (Wt Ad) during the last 10-min blocks were as following (percentage of mean \pm SEM of baseline): Wt Ad control, $143.4 \pm 1.3 \%$; Wt control, $132.0 \pm 0.6 \%$; Wt enrich, $140.0 \pm 1.4 \%$; Het control, $118.9 \pm 1.1 \%$; Het enrich, $128.6 \pm 0.6 \%$; Homo control, $102.1 \pm 1.2 \%$; and Homo enrich, $105.6 \pm 0.9 \%$. One-way ANOVA pairwise comparisons by Dunn's method and $t$-test showed that adult control vs. aged Wt control, Wt control vs. Het control, and both Wt and Het controls vs. Homo control were all significantly different with $P<0.001$. Wt and Het enriched vs. their corresponding controls were also significantly different with $P<0.005$ and $P<0.001$, respectively. Enriched aging Wt achieved almost as good as that of adult control. Both control and enriched $\mathrm{Ng}-/-$ showed no LTP under the condition of HFS and they were not significantly different from each other. Representative traces of the fEPSP before (1) and $60 \mathrm{~min}$ after (2) HFS are shown with calibration, $1 \mathrm{mV}$ and 5 msec.

and Barnes 2003; Gant et al. 2006) and/or changes in the expression pattern of NMDA receptors (Magnusson et al. 2005, 2006). Even with the shift in the signaling mechanism, $\mathrm{Ng}-/-$ still performed relatively poorly comparing to $\mathrm{Ng}+/+$ and $\mathrm{Ng}+/-$ mice both in the control as well as in the enriched groups. These results suggest that among the aged animals $\mathrm{Ng}$ still plays an important role in the cognitive behaviors but contributes less in the enrichment-mediated improvement during aging.

Aging-related impairments of hippocampus-dependent memory may be caused, in part, by altered synaptic mechanisms including LTP (Rosenzweig and Barnes 2003). The magnitude of both the early and late phase of LTP in hippocampal CA1 region induced by HFS is significantly reduced in the aged compared to young adult mice (Bach et al. 1999; Watson et al. 2002). The present data showed that the magnitude of LTP of control Ng+/+ was lower than that of the young adults; however, the enriched aging mice nearly regained the magnitude comparable to that of the control young adults (Fig. 5). Though the level of $\mathrm{Ng}$ in the enriched aging $\mathrm{Ng}+/+$ mice increased to a level greater than the young adults, this enrichment-related increase in $\mathrm{Ng}$ level and magnitude of LTP did not contribute significantly to their improvement of behavioral performance. On the other hand, $\mathrm{Ng}-/$ - mice exhibited negligible LTP and enrichment did not affect its magnitude; however, enrichment profoundly improved their performance in the step-down fear avoidance test. In this test, animals associated the platform within a given context (spatial recognition) with a foot shock (fear) when they step down from it. Successful performance of this task requires the integrity of both amygdala and hippocampus. Since the NMDA receptormediated signaling, such as HFS-induced LTP, is impaired in $\mathrm{Ng}-/-$ mice, a separate input from amygdala resulting from aversive fear experiences probably triggered a pathway for spatial recognition in the aged $\mathrm{Ng}-/-$ mice. It is likely that enrichment enhances this subcortical input from amygdala to entorhinal cortex and hippocampal formation in these aged $\mathrm{Ng}-/-$ mice via the separate pathway to compensate their deficits in the NMDA receptor-mediated signaling. This prediction is consistent with the reported notion that aging causes a gradual shift from NMDA receptor-dependent to voltage-dependent calcium channeldependent plasticity mechanisms (Rosenzweig and Barnes 2003). It seemed that this and/or other similar types of shift are accelerated by enrichment in the aging $\mathrm{Ng}-/-$ mice.

Behavioral testing for the hippocampus-dependent spatial memory with Barnes maze and food-motivated radial arm maze showed that the enriched groups performed better in certain aspects of these tasks. In the Barnes maze, all three genotypes of the enriched mice exhibited shorter latency time than their controls to locate the escape box throughout training and greater preference to the target quadrant during probe test. These enrichmentrelated improvements cannot be accounted entirely for their increasing acuity of spatial memory because the enriched groups already exhibited shorter latency time at the beginning of the trial. The net gain due to enrichment, though significant, may also result from their increasing motivation to want to stay in the dark place. The enrichment-related behavioral changes before training were also evident in the step-down fear avoidance task, especially $\mathrm{Ng}+/-$ and $\mathrm{Ng}-/-$ mice, which exhibited a greater immobility to novel environment. In the radial arm maze, all three genotypes of the enriched groups consumed all the baits faster than their respective controls at the end of training. However, enrichment did not improve their reference (spatial) memory at the end of trial. Enrichment also had negligible benefit in improving the working memory of $\mathrm{Ng}+/+$ and $\mathrm{Ng}+/-$ mice, but seemed to have a positive effect on $\mathrm{Ng}-/-$. Based on the results from these three behavioral tests that compare the spatial memory motivated by the escape to a dark place (Barnes maze), fear for the aversive foot shock (step-down fear avoidance), and food seeking (radial arm maze), we conclude that long-term enrichment produced much less benefit for the aged $\mathrm{Ng}+/+$ and $\mathrm{Ng}+/$ - than for the aged $\mathrm{Ng}-/$ - mice on the spatial memory per se.

Similar to our previous results with young adults, enrichment increased the hippocampal $\mathrm{Ng}$ level in $\mathrm{Ng}+/+$ and $\mathrm{Ng}+/-$ mice and CREB in all three genotypes but without significant changes in p42 ERK and $\alpha$ CaMKII. The increase in Ng among $\mathrm{Ng}+/+$ and $\mathrm{Ng}+/$ - mice could contribute to the positive effect of enrichment on the LTP of these mice even without the corresponding change in $\alpha$ CaMKII. The increase in CREB among $\mathrm{Ng}-/-$ mice failed to enhance the LTP of this mutant, again confirming the essential role of $\mathrm{Ng}$ in the expression of HFSinduced LTP; however, the increase in this signaling protein may have positive impact in their behavioral performances.

In conclusion, environmental enrichment enhances the protein levels of $\mathrm{Ng}$ and $\mathrm{CREB}$ among aged $\mathrm{Ng}+/+$ and $\mathrm{Ng}+/-$ mice and increase their LTP magnitudes. Without $\mathrm{Ng}, \mathrm{Ng}-/-$ 
mice, the enrichment-related increase in CREB fails to rescue the impairment of these mutant mice in the expression of LTP. The enrichment-related increase in LTP in the $\mathrm{Ng}+/+$ and $\mathrm{Ng}+/-$ mice does not bring about much improvement in their spatial memory. In contrast, $\mathrm{Ng}-/-$, without enhanced expression of LTP, did exhibit enrichment-related improvement of certain cognitive behaviors. This paradoxical observation suggests that, during aging, $\mathrm{Ng}-/-$ mice, which have inherently depressed NMDA receptor-dependent response, have developed an alternative mechanism to enhance the plasticity through environmental stimuli. This enrichment-related response appears to be unique for the aged $\mathrm{Ng}-/-$ but not the young adult mice. Recently, it has been reported that aging itself can rescue certain behavioral deficits in the $K_{v} \beta 1.1$ knockout mice (Need et al. 2003), suggesting the development of an alternative plasticity mechanism in the aged animal. The underlying aging-related changes in the neural circuitry that result in the gain of function of $\mathrm{Ng}-/$ - mice to environmental stimuli warrant further investigation.

\section{Materials and Methods}

\section{Mice and enrichment protocol}

The use of animals was approved by the National Institute of Child Health and Human Development Animal Care and Use Committee. All mice, wild type and mutants, were bred in house and have been back-crossed into C57BL/6 more than 10 generations from the original $129 / \mathrm{Sv} \times \mathrm{C} 57 \mathrm{BL} / 6$ mixed background. Animals were maintained on a 12-h light/12-h dark cycle, and the behavioral tests were carried out during the light period. Mice of different genotypes 20-23 mo of age and of mixed gender were group-housed in either a control cage $(30 \mathrm{~cm}$ length $\times 19 \mathrm{~cm}$ width $\times 13 \mathrm{~cm}$ height $)$ or an enriched cage $(48 \mathrm{~cm}$ length $\times 26$ $\mathrm{cm}$ width $\times 16 \mathrm{~cm}$ height). The enrichment cages contained rodent toys of different shapes and colors and an exercise running wheel that were changed weekly. Mice in the enriched group were also forced to exercise on a treadmill daily. Exercise on the treadmill was started with a slower speed and shorter duration and from the second month on it was at a speed of $15 \mathrm{~m} / \mathrm{min}$ for 15 min daily until the conclusion of the experiment. Electrophysiology and behavioral tests were commenced after at least 3 mo of enrichment and electrophysiological recording would not use previously tested animals. Animals used for Barnes maze tasks were not used for radial arm maze and vise versa, while stepdown fear conditioning always used previously tested ones. Thus, the same animal size was not used in all tests, and the $n$ number will be indicated at each test. At the conclusion of the behavioral testing, the animals were killed, and both the right and the left hippocampi were dissected and kept frozen at $-80^{\circ}$ for later immunoblot analyses.

\section{Barnes maze}

The Barnes spatial navigation task on "dry land" was conducted for these aged animals instead of Morris water maze to reduce their stress. The maze is a white circular board of $1.0 \mathrm{~m}$ in diameter, with 12 holes $(7 \mathrm{~cm}$ diameter) equally spaced and $18 \mathrm{~cm}$ away from the perimeter. A black Plexiglas box was placed underneath one of the holes as an escape chamber. The maze was raised $60 \mathrm{~cm}$ from the floor and the movement of the mice was monitored by a video system to record the latency for entering the escape box (or at least three paws in the box for $>3 \mathrm{sec}$ ), distance traveled, and time spent in each quadrant. Three blocks of trial and three trials per block (starting at different quadrant) were conducted each day for four successive days. In each trial, mouse was allowed to navigate till entering the escape box or until $60 \mathrm{sec}$ had elapsed. On day 5, a probe trial without the escape box was conducted; time spent in each quadrant within 1-min allowed time was recorded.

\section{Step-down fear conditioning}

The mouse was placed on a plastic platform $(10 \times 9 \times 2.5 \mathrm{~cm}$ height), which was placed inside a stainless steel box $(23 \times 23 \times 23 \mathrm{~cm})$ having a metal grid floor for electrical shock. When the mouse stepped down onto the grid and had all four paws on the grid, it received a 2 -sec, $0.5-\mathrm{mA}$ foot shock and was immediately returned to its home cage. Twenty-four hours after such conditioning trial, the mouse was returned to the platform in the shocking box for testing its retention time from stepping down onto the grid or when 15 min had elapsed. The foot shock was omitted during testing.

\section{Radial arm maze}

Training trials in radial arm maze were performed as described previously (Huang et al. 2006). Training consisted of two daily trials; there were 20 training trials in 10 consecutive days. During the whole period of trial, food was only available from 4:00 p.m. to $8: 00 \mathrm{p} . \mathrm{m}$. but with unlimited water, and the body weight of the animal was closely monitored to avoid $>20 \%$ reduction. Animals were group-habituated first with baits (sugar pellet of $\sim 10$ $\mathrm{mg}$ ) all over the arms, and then with baits placed only at four intended arms (\#1, 2, 4, and 7) used for later testing, and each session lasted $10 \mathrm{~min}$. In the actual training, only one pellet was placed at the end of each intended arm, and the mice, one at a time, were placed at the center area for 5 sec before simultaneously opening all the doors to the arms. Each trial lasted 3 min or until all four baits were consumed, during which all entries were recorded either into baited or unbaited arms and either with or without consumption of the bait. In tabulating the results, the percentage of working memory error was defined as any reentry among total entries and the percentage of reference memory error as entries into unbaited arms and those without consumption of bait when entering baited arms out of total entries.

\section{Immunoblot analysis}

Each hippocampus was homogenized in $400 \mu \mathrm{L}$ of buffer containing $50 \mathrm{mM}$ Tris/Cl (pH 7.8), 2 mM EDTA, 2 mM EGTA, $2 \mathrm{mM}$ DTT, $50 \mathrm{mM} \mathrm{KF}, 5 \mathrm{mM}$ Na-pyrophosphate, $50 \mathrm{nM}$ okadaic acid, $50 \mu \mathrm{M}$ AEBSF, $5 \mu \mathrm{g} / \mathrm{mL}$ of leupeptin, and $1 \%$ SDS. Protein concentration was determined by BCA reagent, and normally $30 \mu \mathrm{g}$ of protein was loaded per lane (4 $\mathrm{mm}$ wide and $1.5 \mathrm{~mm}$ thick) onto an 8\%-16\% gradient gel for SDS-PAGE. Proteins were transferred onto nitrocellulose membrane after electrophoresis; the lower portion of the membrane was used for analysis of $\mathrm{Ng}$ and the top portion for CREB, $\alpha$ CaMKII, ERK, and actin consecutively following each stripping. Control and enriched samples of the same genotype were run on the same gel, and the same were for control samples of all genotypes including adult wild-type control for direct comparisons. After primary and secondary immunoreactions, ECL reagent was used to reveal the proteins in the linear range of exposure for each antibody. Relative intensities of protein bands were scanned and quantified using Kodak Imaging Station and its analysis software. For changes in protein expression, all relative intensities were first normalized against actin intensities before comparison.

\section{Electrophysiology}

Electrophysiological recordings were carried out as previously described (Huang et al. 2006) except that the present experiments were done at $30^{\circ} \mathrm{C}$ instead of room temperature. Mice used have been through at least 3 mo of control or enriched period but were not previously tested for any task. Both right and left hippocampus were used for recordings by two separate equipments, and the data were combined. Transverse hippocampal slices $(400 \mu \mathrm{m})$ were kept for recovery after slicing for $1-2 \mathrm{~h}$ in oxygenated $(95 \%$ $\mathrm{O}_{2} / 5 \% \mathrm{CO}_{2}$ ) artificial CSF (aCSF) containing the following: 124 $\mathrm{mM} \mathrm{NaCl}, 4.9 \mathrm{mM} \mathrm{KCl}, 1.3 \mathrm{mM} \mathrm{MgSO}_{4}, 2.5 \mathrm{mM} \mathrm{CaCl}_{2}, 1.2 \mathrm{mM}$ $\mathrm{KH}_{2} \mathrm{PO}_{4}, 25.6 \mathrm{mM} \mathrm{NaHCO}, 10 \mathrm{mM}$ D-glucose $(\mathrm{pH} \mathrm{7.4).} \mathrm{The}$ slices were submerged in the chamber superfused with oxygenated aCSF at a flow rate of $2 \mathrm{~mL} / \mathrm{min}$. Glass electrodes (1-4 M $\Omega$ ) filled with aCSF were used both for the stimulation of Schaffer 
collateral/commissural fibers and for the recording of field EPSPs (fEPSPs) from the stratum radiatum of the CA1 area. The slope of the fEPSP was calculated for indexing the potentiation. After maintaining a stable baseline at a current that gave $1 / 3$ of the maximum response, the slice was subjected to a high frequency stimulation of $100 \mathrm{~Hz}$ for $1 \mathrm{sec}$. Potentials were amplified with an Axon Multiclamp 700B, digitized by CED Power 1401 (Cambridge Electronic Design), and analyzed by Signal 2 software (Cambridge Electronic Design). Potentiations after HFS were expressed as a percentage of the initial baseline recordings. For comparisons between responses of different groups, the last 10min blocks of recording were analyzed.

\section{Statistical analysis}

Results were expressed as mean \pm SEM. Statistical comparisons were made by one-way ANOVA and using the Holm-Sidak method for pairwise comparisons unless otherwise indicated to identify the significant differences. In all cases, $P<0.05$ was considered significant.

\section{Acknowledgments}

We thank Daniel Abebe, Lemlem Alemu, Gerber Romero, and Marlon Calvaro for taking care of the animals' welfare, maintaining enrichment environment, and treadmill exercises for mice at various phases of the study. This study was supported by the Intramural Research Program of the NIH, National Institute of Child Health and Human Development.

\section{References}

Arendash, G.W., Garcia, M.F., Costa, D.A., Cracchiolo, J.R., Wefes, I.M., and Potter, H. 2004. Environmental enrichment improves cognition in aged Alzheimer's transgenic mice despite stable $\beta$-amyloid deposition. Neuroreport 15: 1751-1754.

Bach, M.E., Barad, M., Son, H., Zhuo, M., Lu, Y.F., Shih, R., Mansuy, I., Hawkins, R.D., and Kandel, E.R. 1999. Age-related defects in spatial memory are correlated with defects in the late phase of hippocampal long-term potentiation in vitro and are attenuated by drugs that enhance the cAMP signaling pathway. Proc. Natl. Acad. Sci. 96: $5280-5285$.

Bennett, J.C., McRae, P.A., Levy, L.J., and Frick, K.M. 2006. Long-term continuous, but not daily, environmental enrichment reduces spatial memory decline in aged male mice. Neurobiol. Learn. Mem. 85: 139-152.

Frick, K.M., Stearns, N.A., Pan, J.Y., and Berger-Sweeney, J. 2003. Effects of environmental enrichment on spatial memory and neurochemistry in middle-aged mice. Learn. Mem. 10: 187-198.

Gant, J.C., Sama, M.M., Landfield, P.W., and Thibault, O. 2006. Early and simultaneous emergence of multiple hippocampal biomarkers of aging is mediated by $\mathrm{Ca}^{2+}$-induced $\mathrm{Ca}^{2+}$ release. J. Neurosci. 26: 3482-3490.

Huang, Y.Y. and Kandel, E.R. 2006. Age-related enhancement of a protein synthesis-dependent late phase of LTP induced by low frequency paired-pulse stimulation in hippocampus. Learn. Mem. 13: $298-306$.

Huang, K.P., Huang, F.L., Jager, T., Li, J., Reymann, K.G., and Balschun, D. 2004. Neurogranin/RC3 enhances long-term potentiation and learning by promoting calcium-mediated signaling. J. Neurosci.
24: $10660-10669$.

Huang, F.L., Huang, K.P., Wu, J., and Boucheron, C. 2006. Environmental enrichment enhances neurogranin expression and hippocampal learning and memory but fails to rescue the impairments of neurogranin null mutant mice. J. Neurosci. 26: 6230-6237.

Kempermann, G., Gast, D., and Gage, F.H. 2002. Neuroplasticity in old age: Sustained fivefold induction of hippocampal neurogenesis by long-term environmental enrichment. Ann. Neurol. 52: 135-143.

Kobayashi, S., Ohashi, Y. and Ando, S. 2002. Effects of enriched environments with different durations and starting times on learning capacity during aging in rats assessed by a refined procedure of the Hebb-Williams maze task. J. Neurosci. Res. 70: $340-346$.

Lee, H.K., Min, S.S., Gallagher, M., and Kirkwood, A. 2005. NMDA receptor-independent long-term depression correlates with successful aging in rats. Nat. Neurosci. 8: 1657-1659.

Magnusson, K.R., Bai, L., and Zhao, X. 2005. The effects of aging on different C-terminal splice forms of the zeta1(NR1) subunit of the $\mathrm{N}$-methyl-d-aspartate receptor in mice. Brain Res. Mol. Brain Res. 135: $141-149$.

Magnusson, K.R., Kresge, D., and Supon, J. 2006. Differential effects of aging on NMDA receptors in the intermediate versus the dorsal hippocampus. Neurobiol. Aging 27: 324-333.

Mattson, M.P., Duan, W., Lee, J., and Guo, Z. 2001. Suppression of brain aging and neurodegenerative disorders by dietary restriction and environmental enrichment: Molecular mechanisms. Mech. Ageing Dev. 122: 757-778.

Miyakawa, T., Yared, E., Pak, J.H., Huang, F.L., Huang, K.P., and Crawley, J.N. 2001. Neurogranin null mutant mice display performance deficits on spatial learning tasks with anxiety related components. Hippocampus 11: 763-775.

Need, A.C., Irvine, E.E., and Giese, K.P. 2003. Learning and memory impairments in $\operatorname{Kv} \beta$ 1.1-null mutants are rescued by environmental enrichment or ageing. Eur. J. Neurosci. 18: 1640-1644.

Pak, J.H., Huang, F.L., Li, J., Balschun, D., Reymann, K.G., Chiang, C., Westphal, H., and Huang, K.P. 2000. Involvement of neurogranin in the modulation of calcium/calmodulin-dependent protein kinase II, synaptic plasticity, and spatial learning: A study with knockout mice. Proc. Natl. Acad. Sci. 97: 11232-11237.

Rosenzweig, E.S. and Barnes, C.A. 2003. Impact of aging on hippocampal function: Plasticity, network dynamics, and cognition. Prog. Neurobiol. 69: 143-179.

Watson, J.B., Khorasani, H., Persson, A., Huang, K.P., Huang, F.L., and O'Dell, T.J. 2002. Age-related deficits in long-term potentiation are insensitive to hydrogen peroxide: Coincidence with enhanced autophosphorylation of $\mathrm{Ca}^{2+} /$ calmodulin-dependent protein kinase II. J. Neurosci. Res. 70: 298-308.

Wu, J., Li, J., Huang, K.P., and Huang, F.L. 2002. Attenuation of protein kinase $\mathrm{C}$ and cAMP-dependent protein kinase signal transduction in the neurogranin knockout mouse. J. Biol. Chem. 277: 19498-19505.

Wu, J., Huang, K.P., and Huang, F.L. 2003. Participation of NMDA-mediated phosphorylation and oxidation of neurogranin in the regulation of $\mathrm{Ca}^{2+}$ - and $\mathrm{Ca}^{2+} /$ calmodulin-dependent neuronal signaling in the hippocampus. J. Neurochem. 86: 1524-1533.

Zhabotinsky, A.M., Camp, R.N., Epstein, I.R., and Lisman, J.E. 2006. Role of the neurogranin concentrated in spines in the induction of long-term potentiation. J. Neurosci. 26: 7337-7347.

Received May 18, 2007; accepted in revised form June 4, 2007. 


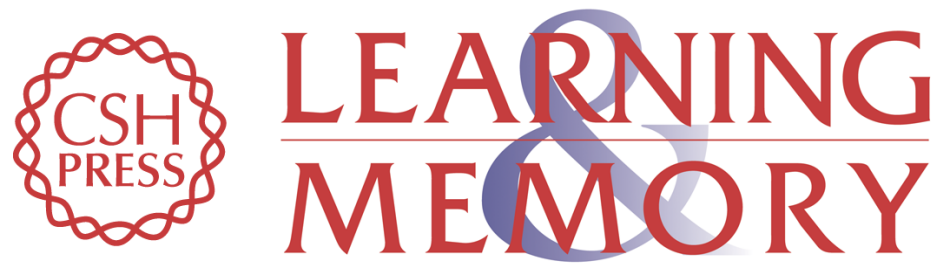

\section{Long-term enrichment enhances the cognitive behavior of the aging neurogranin null mice without affecting their hippocampal LTP}

Freesia L. Huang, Kuo-Ping Huang and Catherine Boucheron

Learn. Mem. 2007, 14:

Access the most recent version at doi:10.1101//m.636107

References This article cites 22 articles, 9 of which can be accessed free at: http://learnmem.cshlp.org/content/14/8/512.full.html\#ref-list-1

License

Email Alerting

Receive free email alerts when new articles cite this article - sign up in the box at the Service top right corner of the article or click here. 